\title{
Synthesis and Docking Study of 2-Aryl-4,5-diphenyl-1H-imidazole Derivatives as Lead Compounds for Antimalarial Agent
}

\author{
Ika Septiana ${ }^{1}$, Bambang Purwono $^{1^{*}}$, Chairil Anwar ${ }^{1}$, Beta Achromi Nurohmah ${ }^{1}$, and Jufrizal Syahri ${ }^{2}$ \\ ${ }^{1}$ Department of Chemistry, Faculty Mathematics and Natural Sciences, Universitas Gadjah Mada, \\ Sekip Utara, PO BOX BLS 21, Yogyakarta 55281, Indonesia \\ ${ }^{2}$ Department of Chemistry, Faculty of Mathematics and Natural Sciences, Universitas Muhammadiyah Riau, \\ Pekanbaru 28156, Indonesia
}

${ }^{*}$ Corresponding author:

email:purwono.bambang@ugm.ac.id

Received: July 20, 2021

Accepted: September 7, 2021

DOI: $10.22146 /$ ijc. 67777

\begin{abstract}
Series of 2-aryl-4,5-diphenyl-1H-imidazole derivatives of 2-(4-hydroxy-3methoxyphenyl)-4,5-diphenyl-1H-imidazole (1), 2-(4,5-dimethoxyphenyl)-4,5-diphenyl$1 \mathrm{H}$-imidazole (2) and 2-(4-methoxyphenyl)-4,5-diphenyl-1H-imidazole (3) were produced and evaluated for their in vitro antimalarial activities against the chloroquinesensitive Plasmodium falciparum 3D7 strain. A molecular docking study was also carried out against the crystal protein of Plasmodium falciparum dihydrofolate reductasethymidylate synthase (PfDHFR-TS) (PDB ID: 1J3I.pdb) to predict the interaction between the compounds and protein. The physicochemical and pharmacokinetic parameters were computationally performed to predict the parameters of the absorption, distribution, metabolism, excretion, and toxicity (ADMET). Imidazoles were synthesized from aryl aldehyde derivatives with benzyl and ammonium acetate in glacial acetic acid using microwave-assisted-organic synthesis. Compounds 1, 2, and 3 were produced in 64.33, 50.56, and 70.55\% yields, respectively. The $I C_{50}$ of compounds 1, 2, and 3 against chloroquine-sensitive Plasmodium falciparum $3 D 7$ strain was found to be 1.14, 5.28, and $2.42 \mu \mathrm{M}$, respectively. The molecular docking study agreed with the in vitro data by showing the lowest CDOCKER energy for compound 1 (-47.48 kcal/mol), followed by 3 ($43.79 \mathrm{kcal} / \mathrm{mol})$ and $2(-41.47 \mathrm{kcal} / \mathrm{mol})$. The physicochemical and pharmacokinetic parameters showed that imidazoles 1, 2, and 3 obeyed Lipinski rules of five to propose as lead compounds for the antimalarial agents.
\end{abstract}

Keywords: antimalarial; imidazole; 3D7 strain; molecular docking

\section{- INTRODUCTION}

Malaria is a parasitic infectious disease transmitted by the Anopheles mosquito. In 2019, World Health Organization reported that malaria was a threat to approximately half of the world's population [1]. Malaria is produced by the infection of five parasites of the genus of Plasmodium, where most of the mortality are caused by Plasmodium falciparum and Plasmodium vivax [2]. Some effective drugs to treat malaria have been developed, including quinoline, quinine, mefloquine, and artemisinin. Quinoline was used for malaria treatment triggered by $P$. falciparum. However, the resistance of the parasite to this drug has been reported [2]. The resistance parasite has also been developed to other drugs [3]. Different approaches which involve combination therapy of two or more antimalarials have been evaluated and reported to overcome drug resistance of antimalarials.

Imidazoles are members of heterocyclic compounds with various biological activities such as anti-allergic [4], anti-inflammatory [5], antibacterial and antiviral [6], as well as cancer [7]. Imidazoles combined with some heterocycle compounds have also been reported with wide range of antimalarial activity [8-9]. As a part of our search for novel antimalarial agents from theoretical and chemical synthesis, we prepared several imidazoles substituted with methoxy 
and hydroxy groups using a one-step reaction from aryl aldehydes with benzyl and ammonium acetate in glacial acetic acid using microwave-assisted-synthesis. The methoxy and hydroxyl groups have been reported to increase antimalarial activities in compounds of chalcone [10-11], benzimidazoles [12], and coumarins [13].

This study presented the synthesis of simple methoxy imidazoles using the green chemistry technique and their potential as an antimalarial drug (Scheme 1). The activity of antimalaria was determined using $P$. falciparum parasite. The computational methods were performed to predict the interaction formed between the compounds with the co-crystal ligand of Plasmodium falciparum dihydrofolate reductase-thymidylate synthase (PfDHFR-TS) protein (PDB ID: 1J3I.pdb). Furthermore, it was also to predict the physicochemical and pharmacokinetic parameters such as absorption, distribution, metabolism, excretion, and toxicity (ADMET) to support the discovery of lead compounds of antimalaria. The results based on the in vitro assay, molecular docking study, prediction of the physicochemical and pharmacokinetic parameters indicated the good potential of the prepared imidazole derivatives for antimalarial agents and can be used for further modification.

\section{- EXPERIMENTAL SECTION}

\section{Materials}

The materials used in this study were vanillin (3methoxy-4-hydroxybenzaldehyde) (99\% purity Merck, Germany), ammonium acetate (98\% purity Merck, Germany), veratraldehyde (3,4-dimethoxybenzaldehyde) (99\% purity Merck, Germany), anisaldehyde (4- methoxybenzaldehyde) (98\% purity Merck, Germany), benzyl (99\% purity Merck, Germany), glacial acetic acid (99\% purity Merck, Germany), methanol (99\% purity Merck, Germany), and ethanol (99\% purity Merck, Germany). All reagents and solvents were analytical grade and used without further purification.

\section{Instrumentation}

The IR spectra were investigated from potassium bromide $(\mathrm{KBr})$ pellet with FT-IR Spectrophotometer Shimadzu Prestige-21. ${ }^{1} \mathrm{H}$ Nuclear Magnetic Resonance (NMR) was recorded in JEOL JNM ECA $500 \mathrm{MHz}$ with DMSO- $\mathrm{d}_{6}$ as a solvent and tetramethylsilane (TMS) as the internal standard. ${ }^{13} \mathrm{C}$ Nuclear Magnetic Resonance (NMR) was recorded in JEOL JNM ECA $125 \mathrm{MHz}$ with DMSO- $\mathrm{d}_{6}$ solvent. In addition, mass spectra were performed on GC-MS Shimadzu QP-2010S, and the melting points were measured in open capillary tubes using Electrothermal-9100 (uncorrected).

\section{Procedure}

\section{Synthesis of imidazoles 1-3}

Imidazole derivatives 1-3 were synthesized according to the previous method in Singh et al. [14] with modification. A mixture of the appropriate aldehyde (1 mmol), benzyl (1 $\mathrm{mmol})$, ammonium acetate $(10 \mathrm{mmol})$ was dissolved in glacial acetic acid (5 $\mathrm{mL}$ ) and irradiated in a microwave oven for $2 \times 30 \mathrm{~s}$. After the reaction mixture reached room temperature, it was dissolved in ethanol and then poured into distilled water afterward. The solid obtained was then filtered and washed with distilled water. Finally, the crude product was recrystallized from appropriate solvents (methanol or ethanol).

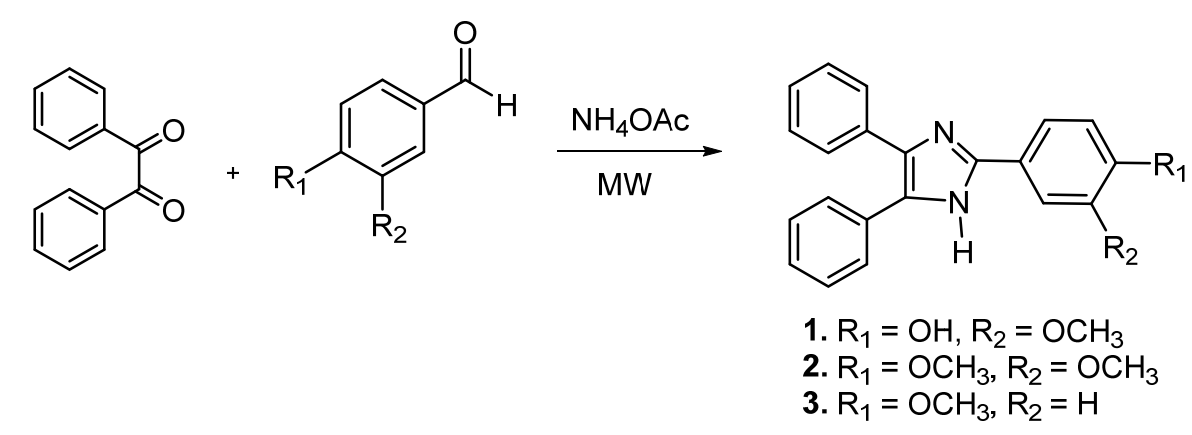

Scheme 1. Synthetic route to targeted imidazole derivatives $(\mathbf{1}, \mathbf{2}$, and $\mathbf{3})$ 
2-(4-hydroxy-3-methoxyphenyl)-4,5-diphenyl-1Himidazole (1). Yield: $64.33 \%$, m.p. $258-262{ }^{\circ} \mathrm{C}\left(\mathrm{Lit}^{20}\right.$. 255-256 $\left.{ }^{\circ} \mathrm{C}\right){ }^{1} \mathrm{H}-\mathrm{NMR}$ (DMSO-d 6 , $\left.500 \mathrm{MHz}\right) \delta$ (ppm): $3.86\left(s, 3 \mathrm{H},-\mathrm{OCH}_{3}\right), 6.87(\mathrm{~d}, 1 \mathrm{H}, \mathrm{H}-\mathrm{Ar}), 7.53(s, 1 \mathrm{H}, \mathrm{Ar})$, 7.30 (t, 4H, H-Ar), 7.55 (d, J=2 Hz, 4H, H-Ar), 7.43 (t, $2 \mathrm{H}, \mathrm{H}-\mathrm{Ar}), 7.65(\mathrm{~d}, J=2 \mathrm{~Hz}, 1 \mathrm{H}, \mathrm{H}-\mathrm{Ar}), 9.28(s, 1 \mathrm{H},-$ $\mathrm{OH}), 12.43(s, 1 \mathrm{H},-\mathrm{NH}) .{ }^{13} \mathrm{C}-\mathrm{NMR}\left(\mathrm{DMSO}-\mathrm{d}_{6}, 125\right.$ $\mathrm{MHz}) \delta$ (ppm): $55.07\left(-\mathrm{OCH}_{3}\right), 109.12$ (C-Ar), 115.60 (C-Ar), 118.35 (C-Ar), 121.94 (C-Ar), 126.35 (C-Ar), 127.02 (C-Ar), 127.57 (C-Ar), 128.38 (C-Ar), 131.34 (CAr), 146.06 (C-Ar), 147.04 (C-Ar), 147.07 (C-Ar). IR $\left(\mathrm{cm}^{-1}\right): 3435(\mathrm{~N}-\mathrm{H}), 1604(\mathrm{C}=\mathrm{N}), 1496(\mathrm{C}=\mathrm{C})$ and 1459 (Ar). MS $(m / z): 342\left(\mathrm{M}^{+}\right)$.

\section{2-(3,4-Dimethoxyphenyl)-4,5-diphenyl-1H-}

imidazole (2). Yield: $50.56 \%$, m.p. $224-225{ }^{\circ} \mathrm{C}\left(\mathrm{Lit}^{21}\right.$, 220-221 ${ }^{\circ} \mathrm{C}$ ), ${ }^{1} \mathrm{H}-\mathrm{NMR}$ (DMSO-d $\left.\mathrm{d}_{6}, 500 \mathrm{MHz}\right) \delta$ (ppm): $3.81\left(3,3 \mathrm{H},-\mathrm{OCH}_{3}\right), 3.85\left(s, 3 \mathrm{H}, \mathrm{OCH}_{3}\right), 7.07(\mathrm{~d}, 1 \mathrm{H}, \mathrm{Ar})$, 7.68 (s, 1H, Ar), 7.55 (t, 4H, H-Ar), 7.44 (t, 4H, H-Ar), 7.30 (t, 1H, H-Ar), 7.23 (d, 2H, H-Ar), 7.39 (d, 2H, HAr), $12.53(s, 1 \mathrm{H},-\mathrm{NH}) .{ }^{13} \mathrm{C}-\mathrm{NMR}$ (DMSO-d $6,125 \mathrm{MHz}$ ) $\delta$ (ppm): $55.58\left(-\mathrm{OCH}_{3}\right), 55.53\left(-\mathrm{OCH}_{3}\right), 149.05(\mathrm{C}-\mathrm{Ar})$, 148.79 (C-Ar), 111.83 (C-Ar), 108.80 (C-Ar), 126.41 (CAr), 128.43 (C-Ar), 145.68 (C-Ar), 135.38 (C-Ar), 136.75 (C-Ar), 131.28 (C-Ar), 128.66 (C-Ar), 127.04 (C-Ar), 117.90 (C-Ar), 123.23 (C-Ar), 128.15 (C-Ar). IR ( $\left.\mathrm{cm}^{-1}\right)$ : $3448(\mathrm{~N}-\mathrm{H}), 1604(\mathrm{C}=\mathrm{N}), 1458(\mathrm{C}=\mathrm{C})$ and $1504($ Ar $)$. MS $(\mathrm{m} / z): 356\left(\mathrm{M}^{+}\right)$.

\section{2-(4-methoxyphenyl)-4,5-diphenyl-1H-imidazole}

(3). Yield: $70.55 \%$, m.p. $230-232{ }^{\circ} \mathrm{C}\left(\mathrm{Lit}^{21}, 228-230{ }^{\circ} \mathrm{C}\right)$ ${ }^{1} \mathrm{H}-\mathrm{NMR}$ (DMSO-d $\left.\mathrm{d}_{6}, 500 \mathrm{MHz}\right) \delta(\mathrm{ppm}): 3.86(s, 3 \mathrm{H},-$ $\mathrm{OCH}_{3}$ ), 7.05 (d, 2H, H-Ar), 8.04 (d, 2H, H-Ar), 7.29 (t, 2H, H-Ar), 7.36 (t, 4H, H-Ar), 7.54 (d, 4H, H-Ar), 12.53 $(s, 1 \mathrm{H},-\mathrm{NH}) .{ }^{13} \mathrm{C}-\mathrm{NMR}$ (DMSO-d $\left.6,125 \mathrm{MHz}\right) \delta(\mathrm{ppm})$ : $55.19\left(-\mathrm{OCH}_{3}\right), 114.09$ (C-Ar), 159.41(C-Ar), 127.14 (CAr), 145.64 (C-Ar), 136.85 (C-Ar), 128.38 (C-Ar), 126.71 (C-Ar), 123.15 (C-Ar), 127.38 (C-Ar), 131.20 (C-Ar). IR $\left(\mathrm{cm}^{-1}\right): 3410(\mathrm{~N}-\mathrm{H}), 1604(\mathrm{C}=\mathrm{N}), 1496(\mathrm{C}=\mathrm{C})$ and 1450 (Ar). MS $(\mathrm{m} / z): 326\left(\mathrm{M}^{+}\right)$.

\section{Antimalarial activity assay}

Antimalaria activity of imidazole derivatives was determined against chloroquine-sensitive Plasmodium falciparum 3D7 strain and conducted according to the previous procedure of Syahri et al. [11]. The $\mathrm{IC}_{50}$ of antimalarial activity was classified according to the following criteria: excellent $(<1 \mu \mathrm{M})$; good $(1-20 \mu \mathrm{M})$; moderate $(20-100 \mu \mathrm{M})$; low $(100-200 \mu \mathrm{M})$; and inactive $(>200 \mu \mathrm{M})$ [15].

\section{Molecular docking study}

A molecular docking study was performed according to previous work by Syahri et al. [16]. The crystal structure of wild-type Plasmodium falciparum dihydrofolate reductase-thymidylate synthase (PfDHFRTS) protein (PDB ID: 1J3I.pdb) was chosen as the protein target. Discovery Studio Visualizer software was used to visualize the interaction.

\section{Prediction of the ADMET parameters}

The physicochemical and pharmacokinetic (ADMET) parameters were predicted using an online webserver admetSAR 2.0 (http://lmmd.ecust.edu.cn/ admetsar2/admetopt/) [17] and ADMETlab webserver http://admet.scbdd.com/ [18]. Drug-like properties were assessed base on the prediction of Lipinski's 'rule of 5 ', including molecular weight, $\log \mathrm{P}$ value, number of hydrogen bonds donor, and acceptor.

The absorption of drugs was generated from some factors, including human intestinal absorption (HIA), membrane permeability [showed by colon cancer cell line (Caco-2)], and human oral bioavailability (HOB). The distribution of drugs varies on parameters such as the plasma protein binding ( $\mathrm{PBB})$, P-glycoprotein inhibitor, and blood-brain barrier (BBB). Metabolism was predicted based on the CYP models for substrate or inhibitor (CYP2D6, CYP3A4, CYP1A2, CYP2C19, CYP2C9, CYP2D6, and CYP3A4). Excretion was expected based on the half-life $\left(t \frac{1}{2}\right)$ and the total clearance. The toxicity of drugs is calculated based on acute oral toxicity, hepatotoxicity, human Ether-à go-gorelated gene (hERG) inhibition, AMES mutagenesis, and carcinogenesis. These factors were predicted and checked by the standard ranges.

Generally, the predicted ADMET parameters were labeled in positive and negative except for plasma protein binding ( $\mathrm{PPB})$, excretion (half-life $(\mathrm{t} 1 / 2)$ and the total clearance), and acute oral toxicity. The plasma protein binding was presented in percentage. The $\mathrm{LD}_{50}$ of acute oral toxicity was categorized into four 
categories, i.e., I ( $\leq 50 \mathrm{mg} / \mathrm{kg})$, II ( $>50 \mathrm{mg} / \mathrm{kg})$, III (> 500 $\mathrm{mg} / \mathrm{kg}$ ), and IV (>5000 $\mathrm{mg} / \mathrm{kg}$ ) with label I and II as positive and III and IV as negative [19]. The half-life factor was classified as low $\left(\mathrm{t}_{1 / 2}<3 \mathrm{~h}\right)$, moderate $\left(3 \mathrm{~h}<\mathrm{t}_{1 / 2}\right.$ $<8 \mathrm{~h})$, and high $\left(\mathrm{t}_{1 / 2}>8 \mathrm{~h}\right)$. Meanwhile, the predicted clearance factor was determined by following the classification of low clearance $(<5 \mathrm{~mL} / \mathrm{min} / \mathrm{kg})$, moderate clearance $(5-15 \mathrm{~mL} / \mathrm{min} / \mathrm{kg})$, and high clearance $(>15$ $\mathrm{mL} / \mathrm{min} / \mathrm{kg}$ ) [18].

\section{- RESULTS AND DISCUSSION}

\section{Synthesis of Imidazole 1-3}

Synthesis of compounds 1, 2, and $\mathbf{3}$ were conducted by reacting benzyl with aryl aldehydes in glacial acetic acid as a solvent in the presence of ammonium acetate $\left(\mathrm{NH}_{4} \mathrm{OAc}\right.$ ) (Fig. 1). The IR spectra of compound $\mathbf{1}, \mathbf{2}$ and 3 showed the sharp band at $1604 \mathrm{~cm}^{-1}$ that indicate the $\mathrm{C}=\mathrm{N}$ functional group and the disappearance of $\mathrm{C}=\mathrm{O}$ aldehydes band. The ${ }^{1} \mathrm{H}-\mathrm{NMR}$ spectra showed one signal of protons -NH (12.43-12.59 ppm) from the fivemembered heterocyclic ring with the integration of one proton, which is described as imidazole. The mass spectroscopy showed the molecular ion was confirmed in a good arrangement with the proposed structures of imidazole 1, 2, and 3. The comparison with some literatures indicated that imidazole $\mathbf{1}, \mathbf{2}$, and $\mathbf{3}$ agreed with previous data in the literatures [20-21].

\section{Antimalarial Activity Assay}

From the $\mathrm{IC}_{50}$ value, in vitro antimalarial activity of imidazoles 1-3 against chloroquine-sensitive Plasmodium falciparum 3D7 strain are presented in Table 1. The $\mathrm{IC}_{50}$ value of compounds $\mathbf{1 - 3}$ showed good antimalarial activity in the range of $1-20 \mu \mathrm{M}$. The best activity was dominated by compound $\mathbf{1}$, possessing a hydroxy and a methoxy group, with $\mathrm{IC}_{50}$ of $1.139 \mu \mathrm{M}$. Modification of one hydroxyl (at a para position from the imidazole ring) to methoxy groups (compound 2) showed a significant decrease of the $\mathrm{IC}_{50}$ to $5.275 \mu \mathrm{M}$. These results showed that hydroxy and methoxy are positively affect the antimalarial activity of the imidazole products in the para and meta position from the imidazole ring, respectively. Moreover, one methoxy substituent at a para position from the imidazole ring still maintains better activity to $2.420 \mu \mathrm{M}$ (compound 3). However, the activities of imidazole $\mathbf{1}$ and $\mathbf{3}$ are still lower than the activity of chloroquine as a positive control $(0.063 \mu \mathrm{M})$.

\section{Molecular Docking Study}

Molecular docking study toward wild-type of Plasmodium falciparum dihydrofolate reductasethymidylate synthase (PfDHFR-TS) protein (PDB ID: 1J3I.pdb) was performed to predict the interaction of the prepared compounds as antimalarial agents. Interactions formed by imidazoles 1-3 were presented in Table 2. The validation of the molecular docking was performed according to the previous work by redocking the co-crystal ligand to the protein [16]. The result showed an RMSD value of $0.6578 \AA$.

Table 1. $\mathrm{IC}_{50}$ of imidazoles $\mathbf{1 - 3}$ against $P$. falciparum 3D7 strain

\begin{tabular}{lcc}
\hline Compound & $\mathrm{IC}_{50}(\mu \mathrm{g} / \mathrm{mL})$ & $\mathrm{IC}_{50}(\mu \mathrm{M})$ \\
\hline $\mathbf{1}$ & 0.39 & 1.14 \\
$\mathbf{2}$ & 1.88 & 5.28 \\
$\mathbf{3}$ & 0.79 & 2.42 \\
$\mathrm{CQ}$ & 0.02 & 0.06 \\
\hline
\end{tabular}

Table 2. Interactions of imidazole 1-3 based on the molecular docking

\begin{tabular}{|c|c|c|}
\hline Ligands & CDOCKER (kcal/mol) & Interactions \\
\hline 1 & -47.4844 & $\begin{array}{l}\text { Hydrogen bonds: GLY44 (2), SER108, SER111, SER167 } \\
\pi \text { bonds: ALA16, LEU40, LEU46, PHE 58, ILE112 }\end{array}$ \\
\hline 2 & -41.4696 & $\begin{array}{l}\text { Hydrogen bonds: SER108, GLY166 } \\
\pi \text { bonds: ALA16, LEU46, MET55, ILE112 }\end{array}$ \\
\hline 3 & -43.7887 & $\begin{array}{l}\text { Hydrogen bonds: GLY166, SER108 } \\
\pi \text { bonds: PRO113, LEU46 (3), MET55, ILE112 (2) }\end{array}$ \\
\hline WR99210 & -54.3200 & $\begin{array}{l}\text { Hydrogen bonds: ALA16, ASP54, CYS15, ILE164, ILE 14, PHE58, SER108, TYR170 } \\
\pi \text { bonds: LEU164, MET55 }\end{array}$ \\
\hline
\end{tabular}

Ika Septiana et al. 
Imidazole 1 was found to form five hydrogen bonding to amino acids of GLY44, SER108, SER111, and SER167, also five $\pi$ interactions to ALA16, LEU40, LEU46, PHE 58, and ILE112. Meanwhile, imidazole 3 displayed two hydrogen bonding to GLY166 and SER108, besides seven $\pi$ interactions to PRO113, LEU46, MET55, and ILE112. On the other hand, imidazole 2 only have two hydrogen bonds to SER108 and GLY166 as well as four $\pi$ interaction to ALA16, LEU46, MET55, and ILE112.

The ligand-protein docking showed a correlation between the CDOCKER energy $(\mathrm{kcal} / \mathrm{mol})$ with the number of hydrogen bonds and hydrophobic bonds. It can be seen that the increasing number of $\mathrm{H}$-bonds at the active site of the receptor was suggested could improve the stability. This result emphasizes that hydrogen bonding interactions are mainly key interactions that affect the stability of the docking poses. As the result, compound $\mathbf{1}$ has the most stable interaction with the crystal protein 1J3I.pdb with the lowest CDOCKER energy of -47.4844 $\mathrm{kcal} / \mathrm{mol}$. Increasing CDOCKER energy was found for 3
$(-43.7887 \mathrm{kcal} / \mathrm{mol})$ and compound 2 (-41.4696 $\mathrm{kcal} / \mathrm{mol}$ ) with a smaller number of hydrogen bonds. On the other hand, the number of hydrophobic interactions also influences the stability of compound $\mathbf{3}$ compared to compound 2. The low docking energy suggested the more stable the interaction of the ligand-protein and might lead to increase activity. Therefore, the interactions formed by imidazoles 1-3 were in agreement with the finding of the in vitro antimalarial assay.

The docking result (Table 3) proposed the significance of the hydroxyl group to determine the antimalarial activity of imidazole derivative 1 by forming hydrogen bonding to the SER167 that leads to an increase in the stability (lower docking energy). In addition, the presence of hydroxyl group in the ortho position to methoxy group in compound $\mathbf{1}$ would lead to the formation of hydrogen bonds from the methoxy group to GLY44 and SER111. It has been reported that the presence of the H-bonds to GLY44 could positively

Table 3. 2D and 3D interactions of imidazole 1-3

Comp.

Ika Septiana et al. 
Table 3. 2D and 3D interactions of imidazole 1-3 (Continued)

Comp.

affect the stability of the interaction to PfDHFR-TS $[12,22]$. Furthermore, only one methoxy group in meta position from the imidazole ring of compound 2 contributes to the formation of a hydrogen bonding to GLY166, leading to the decreasing of antimalarial activity of imidazole 2. However, when only one methoxy is present in para position from the imidazole ring (compound 3), it leads to the formation of a greater number of hydrophobic interactions by the benzene rings than the compound 2 . Thus, the docking pose of imidazole $\mathbf{3}$ was more stable than imidazole $\mathbf{2}$.

\section{Prediction of ADMET Parameters}

Lipinski's 'rule of 5 ' can be used to illustrate the drug-like properties for small molecules that are related to the oral bioavailability characteristic, including $\log \mathrm{P}$ value $(<5)$, molecular weight (less than 500), number of hydrogen bonds for the donor $(\leq 5)$ and acceptor $(\leq 10)$. The defiance of two or more of the guidelines is proposed could produce the poor solubility and permeability of the molecules. Table 4 revealed the drug-likeness parameters of the prepared imidazole 1-3 according to Lipinski's 'rule of 5'. Imidazoles 1-3 followed the rules, implying for being probably orally bioavailable but have relatively poor water solubility with the $\log \mathrm{P}$ higher than 5 .

The ADMET properties of imidazoles 1-3 are presented in Table 4. Imidazoles 1-3 were predicted to have good (positive) human intestinal absorption and membrane permeability (Caco-2 permeability) but have poor oral bioavailability (negative). The poor oral bioavailability might be related to the lipophilicity $(\log \mathrm{P})$ of the molecules. Regarding the distribution parameters, imidazoles 1-3 were predicted to have good distribution (positive) where they can cross the blood-brain barrier easily and have a good plasma protein binding. It also can be noticed that all of the prepared compounds were a non-substate for P-glycoprotein, while imidazoles $\mathbf{1}$ and $\mathbf{2}$ were found to act as P-glycoprotein inhibitors. The induction of P-glycoprotein might reduce the bioavailability [23]. On the contrary, inhibition of these drug transporters could increase the bioavailability of the susceptible drug and might lead to an increased risk of adverse side effects [23-24].

Cytochrome P450s is an important enzyme system that metabolizes more than $90 \%$ of drugs in the liver with the main subtypes of CYP1A2, CYP2C9, CYP2C19, CYP2D6, and CYP3A4 [25]. Therefore, inhibition of CYP450 enzymes might decrease the elimination or change metabolic pathways of the substrates. This condition is the main cause of adverse drug-drug interactions [25]. The result showed that imidazoles 1-3 were predicted to be non-substrates for the subtypes of cytochrome CYP2C9, CYP2D6, and CYP3A4 with a probability value above 0.5 . On the other hand, imidazoles 1 and 2 were predicted to be CYP1A2, CYP2C19, and CYP3A4 inhibitors, while imidazole 3 was an inhibitor for CYP1A2, CYP2C19, CYP3A4, and CYP2D6. This result suggested that imidazoles 1-3 might not be metabolized in the liver.

The excretion parameters were assessed by predicting the half-life $\left(t_{1 / 2}\right)$ and the clearance rate. The 
Table 4. Prediction of physicochemical and ADMET parameters

\begin{tabular}{|c|c|c|c|}
\hline \multirow{2}{*}{ Parameters } & \multicolumn{3}{|c|}{ Compounds } \\
\hline & 1 & 2 & 3 \\
\hline \multicolumn{4}{|l|}{ Drug-likeness } \\
\hline Molecular weight & 342.40 & 356.43 & 326.40 \\
\hline $\mathrm{A} \log \mathrm{P}$ & 5.12 & 5.43 & 5.42 \\
\hline H-bond acceptor & 3 & 3 & 2 \\
\hline H-bond donor & 2 & 1 & 1 \\
\hline \multicolumn{4}{|l|}{ A (Absorption) } \\
\hline Human intestinal absorption (HIA) & $+(0.9897)$ & $+(0.9914)$ & $+(0.9914)$ \\
\hline Human oral bioavailability (HOB) & $-(0.5143)$ & $-(0.5143)$ & $-(0.5429)$ \\
\hline Caco-2 permeability & $+(0.6144)$ & $+(0.7747)$ & $+(0.7613)$ \\
\hline \multicolumn{4}{|l|}{ D (Distribution) } \\
\hline Plasma protein binding (PPB) & $1.067(100 \%)$ & $0.933(100 \%)$ & $0.947(100 \%)$ \\
\hline P-glycoprotein inhibitor & $+(0.6154)$ & $+(0.8269)$ & $+(0.7470)$ \\
\hline Blood-brain barrier penetration (BBB) & $+(0.9695)$ & $+(0.9801)$ & $+(0.9830)$ \\
\hline \multicolumn{4}{|l|}{ M (Metabolism) } \\
\hline CYP450 2C9 substrate & $-(0.8058)$ & $-(0.8078)$ & $-(0.8078)$ \\
\hline CYP450 2D6 substrate & $-(0.7542)$ & $-(0.7623)$ & $-(0.7623)$ \\
\hline CYP450 3A4 substrate & $-(0.5493)$ & $-(0.5479)$ & $-(0.5574)$ \\
\hline CYP450 1A2 inhibition & $+(0.8896)$ & $+(0.9538)$ & $+(0.9710)$ \\
\hline CYP450 2D6 inhibition & $-(0.6718)$ & $-(0.6320)$ & $-(0.5186)$ \\
\hline CYP450 2C9 inhibition & $-(0.7695)$ & $-(0.7720)$ & $-(0.6667)$ \\
\hline CYP450 2C19 inhibition & $+(0.8710)$ & $+(0.8907)$ & $+(0.9226)$ \\
\hline CYP450 3A4 inhibition & $+(0.5480)$ & $+(0.7257)$ & $+(0.7074)$ \\
\hline \multicolumn{4}{|l|}{ E (Excretion)* } \\
\hline Half time $\left(\mathrm{t}_{1 / 2}\right)(\mathrm{h})$ & 1.739 & 1.736 & 2.007 \\
\hline Renal clearance (mL/min/kg) & 1.939 & 1.915 & 1.899 \\
\hline \multicolumn{4}{|l|}{ T (Toxicity) } \\
\hline \multicolumn{4}{|l|}{ Organ toxicity } \\
\hline Hepatotoxicity & $+(0.8500)$ & $+(0.8000)$ & $+(0.8000)$ \\
\hline hERG inhibition & $-(0.5057)$ & $+(0.7353)$ & $-(0.6940)$ \\
\hline Acute oral toxicity & III (0.5713) & III (0.6426) & III (0.6793) \\
\hline \multicolumn{4}{|l|}{ Genomic toxicity } \\
\hline Ames mutagenesis & $+(0.9100)$ & $+(0.9900)$ & $+(0.8500)$ \\
\hline Carcinogenesis & $-(0.9143)$ & $-(0.8714)$ & $-(0.8714)$ \\
\hline
\end{tabular}

half-life of molecules is classified as long $\left(\mathrm{t}_{1 / 2}>3 \mathrm{~h}\right)$ and short half-life $\left(\mathrm{t}_{1 / 2}<3 \mathrm{~h}\right)$. The probability value of compounds 1, 2, and 3 for a long half-life was 0.701, 0.588, and 0.297 , respectively. This result indicated that imidazole 3 was likely to have a shorter half-life than imidazoles $\mathbf{1}$ and 2 . Table 4 shows that imidazoles 1-3 were classified to have a moderate clearance rate (5-15 $\mathrm{mL} / \mathrm{min} / \mathrm{kg}$ ), which was an excellent result. The excretion or drug elimination parameters are reported to be correlated with molecular weight and hydrophilicity [26].

The carcinogenicity of all of the tested imidazoles 1-3 was labeled as inactive compounds (negative). Furthermore, the acute oral toxicity was classified into negative (scale of III) [19]. On the other hand, the Ames mutagenesis was positive for all tested compounds, and 
hERG inhibition was only negative for imidazole $\mathbf{1}$. This result means that imidazoles 1-3 were predicted to be relatively toxic [19]. In conclusion, all of the prepared imidazoles 1-3 have the potential to be developed as antimalarial agents with further modification by lowering the lipophilicity properties $(\log \mathrm{P})$ and toxicity parameters.

\section{- CONCLUSION}

This study presented the antimalarial assay of imidazole derivates 1-3 by assessing the in vitro assay against chloroquine-sensitive Plasmodium falciparum 3D7 strain, molecular docking, and prediction of pharmacokinetic parameters (ADMET). The in vitro assay indicated that compounds $\mathbf{1 - 3}$ could be considered to have good antimalarial activity with $\mathrm{IC}_{50}$ of $1.14,5.28$, and $2.42 \mu \mathrm{M}$, respectively. The molecular docking study supported the in vitro result by showing the lowest CDOCKER energy by compound $1(-47.4844 \mathrm{kcal} / \mathrm{mol})$, followed by $3(-43.7887 \mathrm{kcal} / \mathrm{mol})$ and $2(-41.4696 \mathrm{kcal} / \mathrm{mol})$. According to the prediction of ADMET parameters, imidazole 1, 2, and 3 have the potential as antimalarial drug candidates through further modification.

\section{- ACKNOWLEDGMENTS}

This work was funded by The RTA Grant from Universitas Gadjah Mada for the fiscal year 2019 contract number: 2129/UN1/DITLIT/DIT-LIT/LT/2019.

\section{- AUTHOR CONTRIBUTIONS}

Ika Septiana performed chemical synthesis and formal analysis. Jufrizal Syahri designed the molecular docking and data analysis. Beta Achromi Nurohmah prepared original draft and ADMET analysis. Bambang Purwono designed conceptualization, writing-review, editing and supervision. Chairil Anwar contributed to writing-review.

\section{- REFERENCES}

[1] WHO, 2020, World Malaria Report: 20 Years of Global Progress and Challenges, World Health Organization, Geneva, Switzerland, CC BY-NC-SA 3.0 IGO.

[2] Milner Jr., D.A., 2018, Malaria Pathogenesis, Cold Spring Harb. Perspect. Med., 8 (1), a025569.
[3] Cui, L., Mharakurwa, S., Ndiaye, D., Rathod, P.K., and Rosenthal, P.J., 2015, Antimalarial drug resistance: Literature review and activities and findings of the ICEMR network, Am. J. Trop. Med. Hyg., 93 (3 Suppl.), 57-68.

[4] Kumar, M., Kumar, D., and Raj, V., 2017, Studies on Imidazole and its derivatives with particular emphasis on their chemical/biological applications as bioactive molecules/intermediated to bioactive molecule, Curr. Synth. Syst. Biol., 5 (1), 1000135.

[5] dos Santos Nascimento, M.V.P., Mattar Munhoz, A.C., De Campos Facchin, B.M., Fratoni, E., Rossa, T.A., Mandolesi Sá, M., Campa, C.C., Ciraolo, E., Hirsch, E., and Dalmarco, E.M., 2019, New preclinical evidence of anti-inflammatory effect and safety of a substituted fluorophenyl imidazole, Biomed. Pharmacother., 111, 1399-1407.

[6] Abrigach, F., Rokni, Y., Takfaoui, A, Khoutoul, M., Doucet, H., Asehraou, A., and Touzan, R., 2018, In vitro screening, homology modeling and molecular docking studies of some pyrazole and imidazole derivatives, Biomed. Pharmacother., 103, 653-661.

[7] Guda, R., Kumar, G., Korra, R., Balaji, S., Dayakar, G., Palabindela, R., Myadaraveni, P., Yellu, N.R., and Kasula, M., 2017, EGFR, HER2 target based molecular docking analysis, in vitro screening of 2 , 4, 5-trisubstituted imidazole derivatives as potential antioxidant and cytotoxic agents, J. Photochem. Photobiol., B, 176, 69-80.

[8] Le Manach, C., Gonzàlez Cabrera, D., Douelle, F., Nchinda, A.T., Younis, Y., Taylor, D., Wiesner, L., White, K.L., Ryan, E., March, C., Duffy, S., Avery, V.M., Waterson, D., Witty, M.J., Wittlin, S., Charman, S.A., Street, L.J., and Chibale, K., 2014, Medicinal chemistry optimization of antiplasmodial imidazopyridazine hits from high throughput screening of a SoftFocus kinase library: Part 1, J. Med. Chem., 57 (6), 2789-2798.

[9] Kondaparla, S., Manhas, A., Dola, R.V., Srivastava, K., Puri, S.K., and Katti, S.B., 2018, Design, synthesis and antiplasmodial activity of novel imidazole derivatives based on 7-chloro-4-aminoquinoline, Bioorg. Chem., 80, 204-211. 
[10] Sharma, K., Shrivastava, A., Mehra, R.N., Deora, G.S., Alam, M.M., Zaman, M.S., and Akhter, M., 2017, Synthesis of novel benzimidazole acrylonitriles for inhibition of Plasmodium falciparum growth by dual target inhibition, Arch. Pharm., 351 (1), e1700251.

[11] Syahri, J., Nasution, H., Nurohmah, B.A., Purwono, B., and Yuanita E., 2020, Aminoalkylated chalcone: Synthesis, biological evaluation, and docking simulation as potent antimalarial agents, J. Appl. Pharm. Sci., 10 (6), 001-005.

[12] Purwono, B., Nurohmah, B.A., Fathurrohman, P.Z., and Syahri, J., 2021, Some 2-arylbenzimidazole derivatives as an antimalarial agent: Synthesis, activity assay, molecular docking and pharmacological evaluation, Rasayan J. Chem., 14 (1), 94-100.

[13] Patel, K., Karthikeyan, C., Moorthy, N.S.H.N., Deora, G.S., Solomon, V.R., Lee, H., and Trivedi, P., 2012, Design, synthesis and biological evaluation of some novel 3-cinnamoyl-4-hydroxy-2H-chromen2-ones as antimalarial agents, Med. Chem. Res., 21 (8), 1780-1784.

[14] Singh, R.K., Bhatt, A., and Kant, R., 2016, Design and synthesis of some novel imidazole derivatives as potent antimicrobial \& antimalarial agents, Pharm. Lett., 8 (7), 188-194.

[15] Batista, R., De Jesus Silva Júnior A., and De Oliveira, A.B., 2009, Plant-derived antimalarial agents: new leads and efficient phytomedicines. Part II. Nonalkaloidal natural products, Molecules, 14 (8), 30373072.

[16] Syahri, J., Nasution, H., Nurohmah, B.A., Purwono, B., Yuanita, E., Zakaria, N.H., and Hassan, I., 2020, Design, synthesis and biological evaluation of aminoalkylated chalcones as antimalarial agent, Sains Malays., 49 (11), 2667-2677.

[17] Yang, H., Lou, C., Sun, L., Li, J., Cai, Y., Wang, Z., Li, W., Liu, G., and Tang, Y., 2019, admetSAR 2.0: Webservice for prediction and optimization of chemical ADMET properties, Bioinformatics, 35 (6), 1067-1069.

[18] Xiong, G., Wu, Z., Yi, J., Fu, L., Yang, Z., Hsieh, C., Yin, M., Zeng, X., Wu, C., Lu, A., Chen, X., Hou, T., and Cao, D., 2021, ADMETlab 2.0: An integrated online platform for accurate and comprehensive predictions of ADMET properties, Nucleic Acids Res., 49 (W1), W5-W14.

[19] Yang, H., Sun, L., Wang, Z., Li, W., Liu, G., and Tang, Y., 2018, ADMETopt: A web server for ADMET optimization in drug design via scaffold hopping, J. Chem. Inf. Model., 58 (10), 2051-2056.

[20] Li, J.T., Chen, B.H., Li, Y.W., and Sun, X.L., 2012, Efficient improved synthesis of 2-aryl-4,5diphenylimidazole by heating, Int. J. Adv. Pharm., Biol. Chem., 1 (3), 287-292.

[21] Shelke, K.F., Sapkal, S.B., Sonal, S.S., Madje, B.R., Shingate, B.B., and Shingare, M.S., 2009, An efficient synthesis of 2,4,5-Triaryl- $1 H$-Imidazole derivatives catalyzed by boric acid in aqueous media under ultrasound-irradiation, Bull. Korean Chem. Soc., 30 (5), 1057-1060.

[22] Hadni, H., and Elhallaoui, M., 2019, Molecular docking and QSAR studies for modeling the antimalarial activity of hybrids 4 -anilinoquinolinetriazines derivatives with the wild-type and mutant receptor $p f$-DHFR, Heliyon, 5 (8), e02357.

[23] Finch, A., and Pillans, P., 2014, Importance of Pglycoprotein and its role in drug-drug interactions, Aust. Prescr., 37 (4), 137-139.

[24] Glaeser, H., 2011, "Importance of P-glycoprotein for drug-drug interactions" in Drug Transporters. Handbook of Experimental Pharmacology, Eds. Fromm, M., and Kim, R., Springer, Berlin, Heidelberg, 201, 285-297.

[25] Wu, Z., Lei, T., Shen, C., Wang, Z., Cao, D., and Hou, T., 2019, ADMET evaluation in drug discovery. 19. Reliable prediction of human Cytochrome $\mathrm{P} 450$ inhibition using artificial intelligence approaches, J. Chem. Inf. Model., 59 (11), 4587-4601.

[26] Han, Y., Zhang, J., Hu, C.Q., Zhang, X., Ma, B., and Zhang, P., 2019, In silico ADME and toxicity prediction of ceftazidime and its impurities, Front. Pharmacol., 10, 434. 